\title{
Impact Damage and Residual Compression Strength of CNF/CFRP Hybrid Laminates*
}

\author{
Hiroaki ITO**, Masahiro ARAI**, Kenta TAKEYAMA***, Ning HU**** \\ and Marino QUARESIMIN***** \\ **Department of Mechanical Systems Engineering, Shinshu University, \\ 4-17-1, Wakasato, Nagano-shi, Nagano, 380-8553 Japan \\ E-mail: h-ito@shinshu-u.ac.jp \\ ${ }^{* * *}$ Graduate School of Shinshu University, \\ 4-17-1, Wakasato, Nagano-shi, Nagano, 380-8553 Japan \\ ${ }^{* * *}$ Graduate School \& Faculty of Engineering, Chiba University, \\ 1-33, Inageku, Chiba-shi, Chiba, 263-8522 Japan \\ ${ }^{* * \star * *}$ Department of Management and Engineering, University of Padova, \\ Stradella San Nicola 3, 36100 Vicenza, Italy
}

\begin{abstract}
In the present study, the impact damage of CNF/CFRP hybrid laminates and influence of carbon nanofiber (CNF) interlayer on impact damages were investigated by the drop weight impact tests. Vapor grown carbon fiber (VGCF) has been employed for the toughener of the interlayer on the CFRP laminate. Drop weight impact tests were carried out using "Dynatup" impact test equipment. Damaged area occurring in the interlayer of the CFRP laminate was observed by ultrasonic flaw detection system. The damage properties of the CNF/CFRP hybrid laminates were considered from the viewpoint of the relation between damaged area and impact energy. Moreover, by compression after impact (CAI) tests, the relation between residual compression strength, impact energy and damaged area was investigated. It was confirmed that the damaged area could be reduced, and CAI strength became higher by inserting CNF interlayer. Moreover, the optimal additive amount of VGCF for the interlayer was about $20 \mathrm{~g} / \mathrm{m}^{2}$.
\end{abstract}

Key words: Composite Material, Carbon Nanofiber, Delamination, Impact Test, Interlayer, Compression After Impact Test

\section{Introduction}

From a viewpoint of global warming or energy saving, reduction of $\mathrm{CO}_{2}$ emission associated with consuming fossil fuel came to be mentioned as a key task of each country. To improve the fuel consumption efficiency in the automotive or the aircraft field, the demand of carbon fiber reinforced plastic (CFRP) ${ }^{(1)(2)}$ as an alternative to conventional steel or aluminum alloy increases rapidly.

CFRP is the composite material which impregnated the lightweight plastic with high strength carbon fiber, and has the excellent mechanical property such as high-specific strength and high-specific stiffness. Now, CFRP has already been put to practical use in the sporting goods, such as golf club shaft and fishing rod, chassis of the personal computer, wind turbine blade and so on ${ }^{(3)-(5)}$. Furthermore, the attention degree of CFRP in an aerospace field is very high, in the Boeing 787, the CFRP laminate is applied to more than about $50 \%$ for structural material of body weight. It has been reported that a cruising distance, cruising speed and fuel consumption efficiency improved remarkably ${ }^{(6)(7)}$.

*Received 3 Nov., 2012 (No. 12-0462) [DOI: 10.1299/jmmp.7.381]

Copyright $\odot 2013$ by JSME 
However, the CFRP laminate tends to be formed the delamination by impact applied on its surface. For this problem, the technique, such as inserting the interlayer toughened by the nanoclay or the whisker between the layers of CFRP laminate ${ }^{(8)-(11)}$ and using $\mathrm{Z}$-anchor or z-pin, are examined. Here, the $z$-anchor ${ }^{(12)(13)}$ is the through-thickness reinforcement method in which in-plane carbon fibers are entangled with each other by picking the carbon fiber fabric using special needles. This method can increase the interlaminar fracture toughness of z-anchor reinforced $\mathrm{CF}$ /epoxy laminates inexpensively. However, it is mostly used in resin transfer molding (RTM), and there is almost no report applied to carbon/epoxy prepregs. In contrast, the z-pin ${ }^{(14)-(16)}$ is the technique of improving the delamination resistance of CFRP laminate by embedding high strength rods $1 \mathrm{~mm}$ or less in diameter in the through-thickness direction of composite prepregs. However, the microstructural damage occurs inside the CFRP laminate by embedding the z-pin, so that the in-plane mechanical properties are worsening.

In our previous study ${ }^{(17)-(19)}$, since the manufacturing process was comparatively easy, the method of inserting the interlayer which composed of carbon nanofiber (CNF) between unidirectional prepregs of CFRP laminate was employed, and CNF/CFRP hybrid laminates were manufactured. Mode I and II interlaminar fracture toughness of CNF/CFRP evaluated by double cantilever beam (DCB) and end notched flexure (ENF) tests, respectively. As the results, it was shown clearly that mode I and mode II interlaminar fracture toughness improved by inserting the CNF interlayer. This reason is considered that two factors acted complexly. One is that micro fiber bridging occurred at $\mathrm{VGCF} /$ matrix interface, and the other is that VGCF could control propagation of the delamination which occurred at $\mathrm{CF} /$ matrix interfaces.

So in the present study, CNF/CFRP hybrid laminates inserted CNF interlayer were made using autoclave, and the internal damage which occurred by impact test and residual compression strength were investigated. For the impact test, a drop weight test was carried out and the impact damage occurring at interlaminar was observed with ultrasonic flow detection system. Also, the influence of stacking sequence or interlayer on impact damage was considered from the viewpoint of the relation between impact energy and damaged area. Furthermore, the compression after impact (CAI) test was carried out to CNF/CFRP laminate, and the influence of the additive amount of CNF on the residual compression strength was investigated.

\section{Experimental procedure}

\subsection{Materials and specimens}

CFRP laminates were made using an autoclave (AA-1710-048-M: APC Aerospecialty Inc., Japan). The specimens are composed of carbon/epoxy unidirectional prepregs (P3051S-22, carbon fiber: T700S, resin matrix: \#2500, Toray Industries, Inc., Japan) and CNF interlayer. The stacking sequence of the laminates and additive amount of CNF in an interlayer on each specimen is shown in Table 1. In Table 1, each angle of stacking sequence $\left(0^{\circ}, 45^{\circ}, 90^{\circ}\right.$ or $\left.-45^{\circ}\right)$ shows the relative angle against the carbon fiber direction in prepregs on specimen surface.

In the present study, vapor grown carbon fiber $\left(\mathrm{VGCF}^{(20)}\right.$ : Showa denko K.K., Japan) was used as the toughener for the interlayer. VGCF is about $150 \mathrm{~nm}$ diameter, $10 \mu \mathrm{m}$ mean length and $2.0 \mathrm{~g} / \mathrm{cm}^{3}$ bulk density. The VGCF interlayer was inserted between the prepregs in which the orientation direction of carbon fiber changed (" $\%$ part of Table 1). Typical optical micrograph of cross-section of VGCF/CFRP hybrid laminate is shown in Fig. 1. The additive amount of VGCF in an interlayer was changed to 10,20 or $30 \mathrm{~g} / \mathrm{m}^{2}$. In addition, the VGCF/CFRP laminate became thicker with increasing the additive amount of VGCF, and the thicknesses changed from $3.5 \mathrm{~mm}$ at VGCF $0 \mathrm{~g} / \mathrm{m}^{2}$ to $3.7 \mathrm{~mm}$ at VGCF $30 \mathrm{~g} / \mathrm{m}^{2}$. 
Table 1 Stacking sequence of CFRP laminates and additive amount of VGCF in an interlayer.

\begin{tabular}{|c|c|c|}
\hline Specimen & Stacking sequence & Additive amount of VGCF $\left[\mathrm{g} / \mathrm{m}^{2}\right]$ \\
\hline Type-A & {$\left[0^{\circ}{ }_{2} / 90^{\circ}{ }_{4} / 0^{\circ}{ }_{2}\right]_{\text {sym. }}$} & \multirow{2}{*}{$10,20,30$} \\
\hline Type-B & {$\left[0^{\circ}{ }_{2} / 90^{\circ}{ }_{2} / 0^{\circ}{ }_{2} / 90^{\circ}{ }_{2}\right]_{\text {sym. }}$} & \multirow{2}{*}{$10,3{ }^{\circ}$} \\
\hline Type-C & {$\left[0^{\circ}{ }_{2} / 45^{\circ}{ }_{2} / 90^{\circ}{ }_{2} /-45^{\circ}{ }_{2}\right]_{\text {sym. }}$} & \\
\hline
\end{tabular}

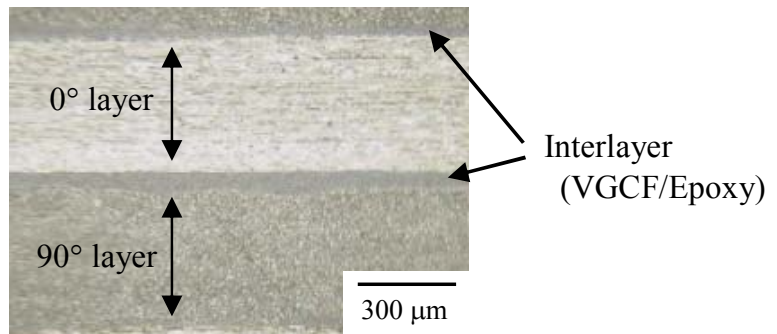

Fig. 1 Optical micrograph of cross-section of VGCF/CFRP hybrid laminate (Type-A).

\subsection{Drop weight impact test}

Drop weight impact tests were carried out using impact test equipment (Dynatup 9250HV: INSTRON). The specimen size for impact test is $100 \mathrm{~mm}$ square, and the weight was dropped in the center of the specimen. A photo and schematic of the equipment is shown in Fig. 2. Impact energy of the drop weight was specified to 2.17, 4.34, 6.52 and 8.69 J. The required impact energy was delivered by adjusting the initial height of the $5.54 \mathrm{~kg}$ cross-head. The impact load was measured by the load cell. The displacement of the cross-head was measured using the laser displacement transducer (LK-G35: Keyence corporation, Japan). The energy absorbed by the specimen can be estimated from these measured data.

The delamination which occurring in the interlayer of the CFRP laminate was observed using the ultrasonic flaw detection system (D-View: Krautkramer Japan Co., Ltd.). Generally the delamination occurs at a number of layers, and they overlapped mutually. Therefore, all delaminations can not be found in the observation from upper or lower surface of the specimen. So, total-projected region of delamination was estimated as the damaged area in this study.

\subsection{Compression after impact test}

To evaluate the residual compression strength of the CFRP laminate which occurring the delamination in the impact test, the compression after impact (CAI) tests were carried out, and CAI strength and CAI elastic modulus were measured. CAI tests were carried out using a universal testing machine (AG-IS250kN: Shimadzu Corporation, Japan). The compression load was applied on the specimen in the parallel direction for $0^{\circ}$ prepregs at cross-head speed $1.0 \mathrm{~mm} / \mathrm{min}$. The photo of jigs used for the CAI test and the schematic of the specimen are shown in Fig. 3(a) and (b), respectively. During CAI test, while measuring load by the load cell attached to equipment, the strain of the specimen was measured using strain gage. CAI strength $\left(\sigma_{U L T}[\mathrm{MPa}]\right)$ was calculated by the following equation ${ }^{(21)}$ :

$$
\sigma_{U L T}=\frac{P}{b t}
$$

where $P$ is the maximum compression load $[\mathrm{N}], b$ is the specimen width [mm] and $t$ is the specimen thickness [mm]. On the other hand, the CAI elastic modulus $E_{X}[\mathrm{GPa}]$ is calculated using Eq. (2). 


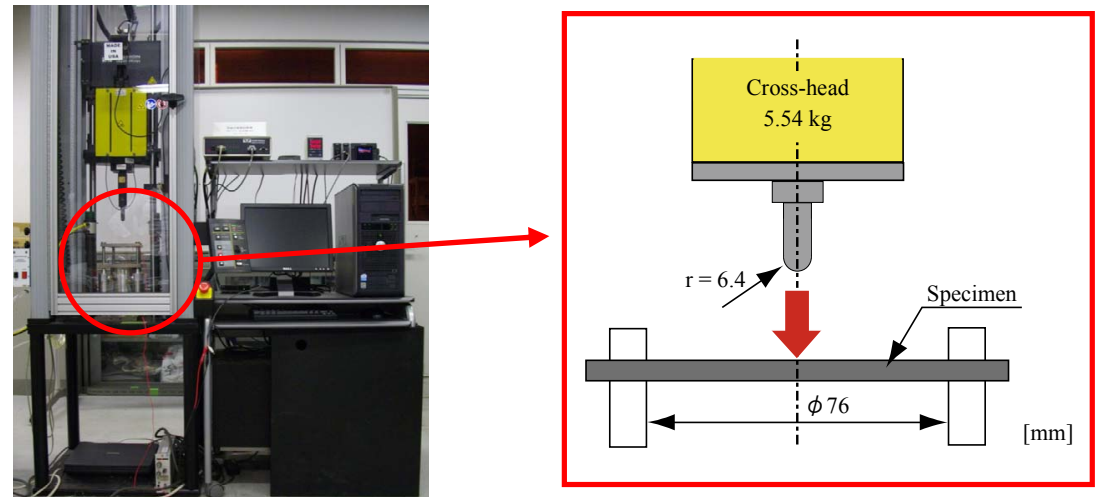

Fig. 2 A photo and schematic of the impact test equipment (Dynatup 9250HV).

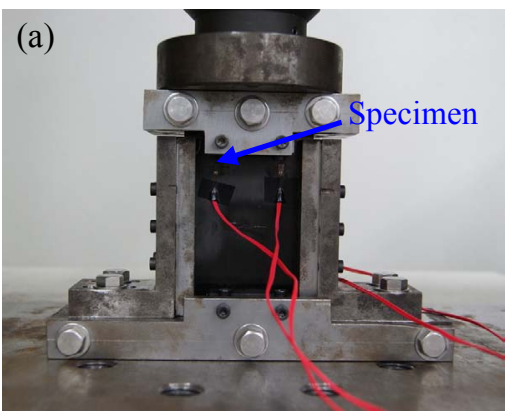

(b)

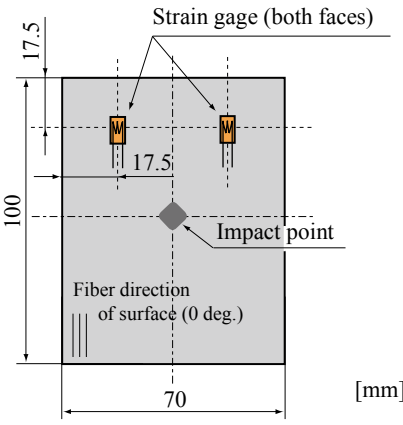

Fig. 3 (a) Photo of jigs and (b) schematic of the specimen for compression after impact test.

$$
E_{X}=\frac{P_{3}-P_{1}}{\left(\varepsilon_{3}-\varepsilon_{1}\right) b t}
$$

where $P_{1}$ and $P_{3}[\mathrm{~N}]$ are loads at strain $\varepsilon_{1}$ and $\varepsilon_{3}$, respectively. In this study, $\varepsilon_{1}$ and $\varepsilon_{3}$ were specified as 0.001 and 0.003 , respectively.

\section{Results of impact test}

\subsection{Drop weight impact test}

To evaluate the damage tolerance for impact loading of VGCF/CFRP hybrid laminates, the drop weight impact tests were carried out. Figure 4 (a) shows load histories of each base laminate, type-A, type-B and type-C, obtained by the impact test at $8.69 \mathrm{~J}$. In type-A and type-B specimens, the load values which acts on a specimen fell notably at the test time about $1 \mathrm{~ms}$. It is guessed that the delamination occurred at this point (about $1 \mathrm{~ms}, 3 \mathrm{~N}$ ). However, in type-C specimen, the remarkable load dropping cannot be found. From these results, it is thought that the fiber orientation angle of the carbon fiber in the CFRP laminate affects the variation of load history related to occurrence of the delamination.

The load histories of VGCF/CFRP hybrid laminates of type-A obtained by the impact test at $8.69 \mathrm{~J}$ are shown in Fig. 4 (b). The profiles of the load histories of VGCF/CFRP laminates were the almost same as that of the base laminate. However, the time when delamination occurs slightly delayed in the case of VGCF/CFRP laminate, and the load value was higher compared with that in the case of base laminate. This tendency can be found also in the other type specimens type-B and type-C.

The load-displacement curves of each base laminate obtained by the impact test at 8.69 $\mathrm{J}$ are shown in Fig. 5. Also in Fig. 5 as well as Fig. 4, the load value was markedly 
decreased at about $1 \mathrm{~mm}$ displacement in the type-A and type-B specimens. Here, by integrating the area which enclosed by the load-displacement curve, the energy absorbed by the specimen can be estimated. The relation of the kinetic energy of the cross-head (impact energy) and the absorbed energy is shown in Fig. 6. It was confirmed that type-A specimens showed slightly higher absorbed energy compared with other type specimens. The influence of additive amount of VGCF on absorbed energy was not accepted.
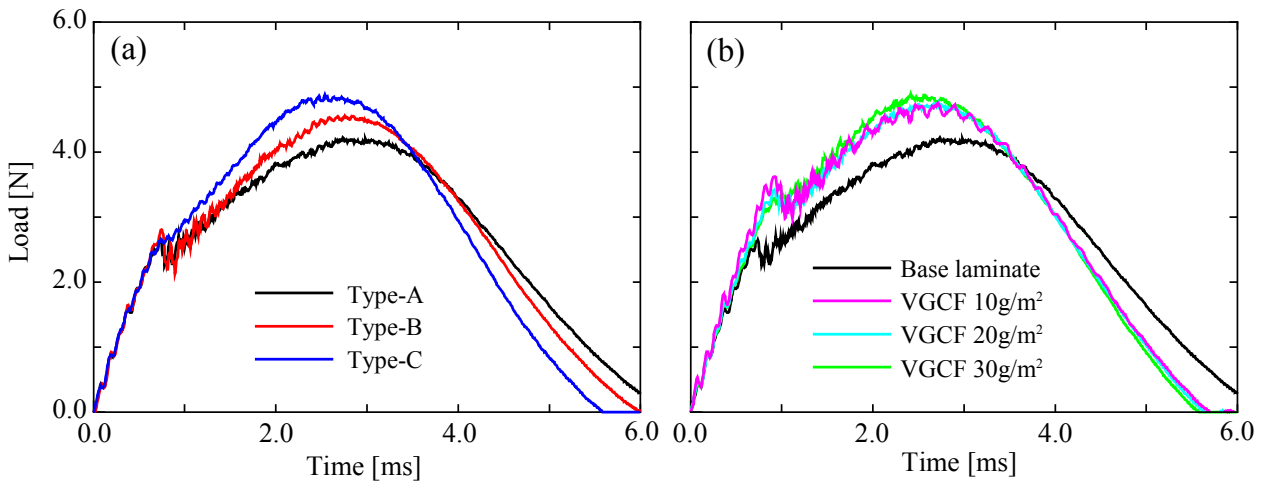

Fig. 4 Load histories of (a) base laminates and (b) VGCF/CFRP hybrid laminates of type-A obtained by impact tests at $8.69 \mathrm{~J}$.

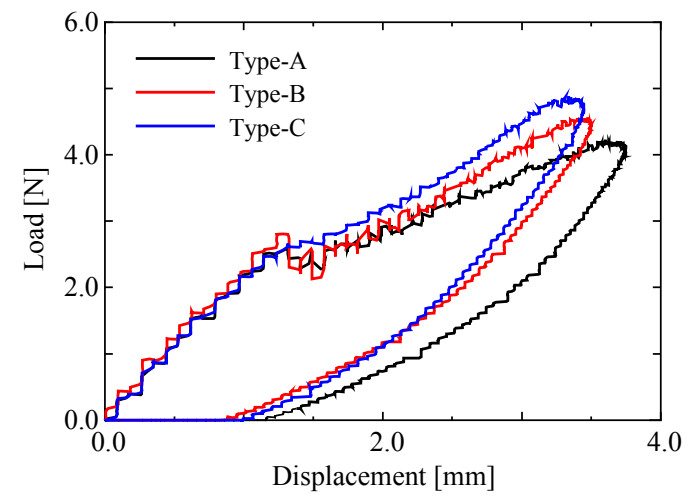

Fig. 5 Typical load-displacement curves of base laminates obtained by impact tests at $8.69 \mathrm{~J}$.

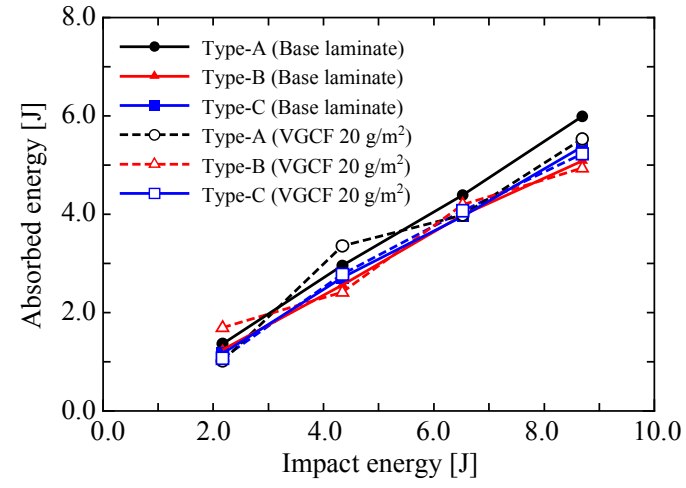

Fig. 6 Relation between absorbed energy and impact energy obtained by impact test. (Base laminate and VGCF/CFRP [VGCF: $\left.20 \mathrm{~g} / \mathrm{m}^{2}\right]$ )

\subsection{Evaluation of damaged area}

Internal damage of each specimen after drop weight impact test was observed using ultrasonic flaw detection system. The images of damaged areas at impact energy $8.69 \mathrm{~J}$ are shown in Fig. 7. Here, the typical images of the base laminate (Type-A, B and C) and VGCF/CFRP laminate (VGCF $20 \mathrm{~g} / \mathrm{m}^{2}$ ) are shown. In these images, we judged that the 
delamination occurred in the red part, and estimated the damaged area. The undamaged part of base laminate is displayed in blue, however, that of VGCF/CFRP is displayed in yellow. This is because that the reflected intensity of echo increased by existing VGCF inside the specimen.

Comparing the damaged areas of three types of base laminate, it was confirmed that the damaged area depended strongly on stacking sequence of the laminates. Moreover, as compared with the results of base laminates, damaged areas of VGCF/CFRP laminates were much smaller by inserting the VGCF interlayer.

Figure 8 shows the relation between impact energy and damaged area. The damaged area of type-A was larger than that of the type-B and type-C, and the difference of damaged area on each type of specimens became large as the impact energy increases. This is caused by the number of interlayer which fiber orientation changes ('/ part in Table 2). Generally the delamination of CFRP laminate occurs the interlayer from which carbon fiber orientation changes. In type-B and type- $\mathrm{C}$ specimens, there are many interlayers on which fiber orientation changes compared with type-A. The more interlayer can bear more impact energy acting on the specimen. As a result, since the impact energy acted to per interlayer became small, the projected region of the damaged area on type- $\mathrm{B}$ and type- $\mathrm{C}$ decreased as compared with type-A. Thus, it was thought by designing stacking sequence with much number of the interlayer from which fiber orientation changes in the CFRP laminates that internal damaged area could be reduced.

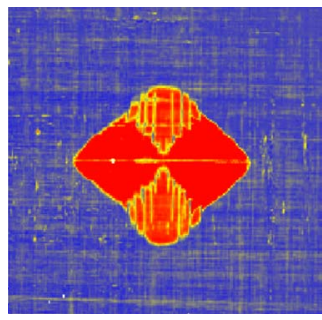

Type-A (Base laminate)

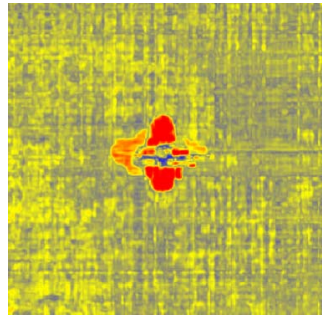

Type-A (VGCF $20 \mathrm{~g} / \mathrm{m}^{2}$ )

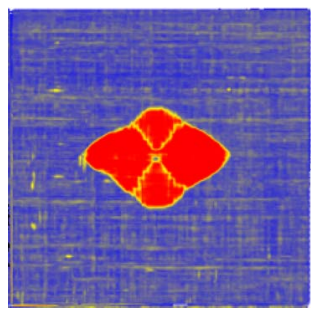

Type-B (Base laminate)

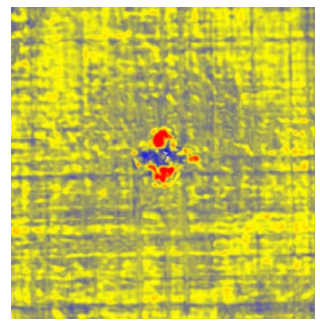

Type-B (VGCF $20 \mathrm{~g} / \mathrm{m}^{2}$ )

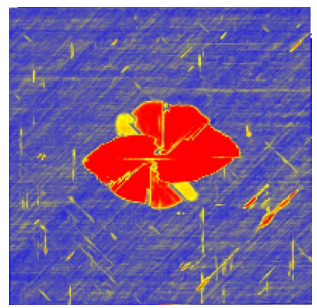

Type-C (Base laminate)

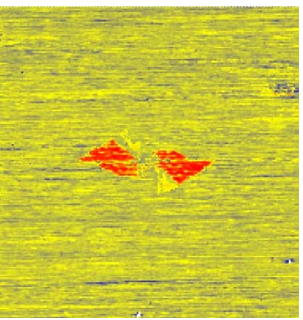

Type-C (VGCF $20 \mathrm{~g} / \mathrm{m}^{2}$ )

Fig. 7 Typical images of damaged area at $8.69 \mathrm{~J}$ observed by ultra sonic flaw detection system.

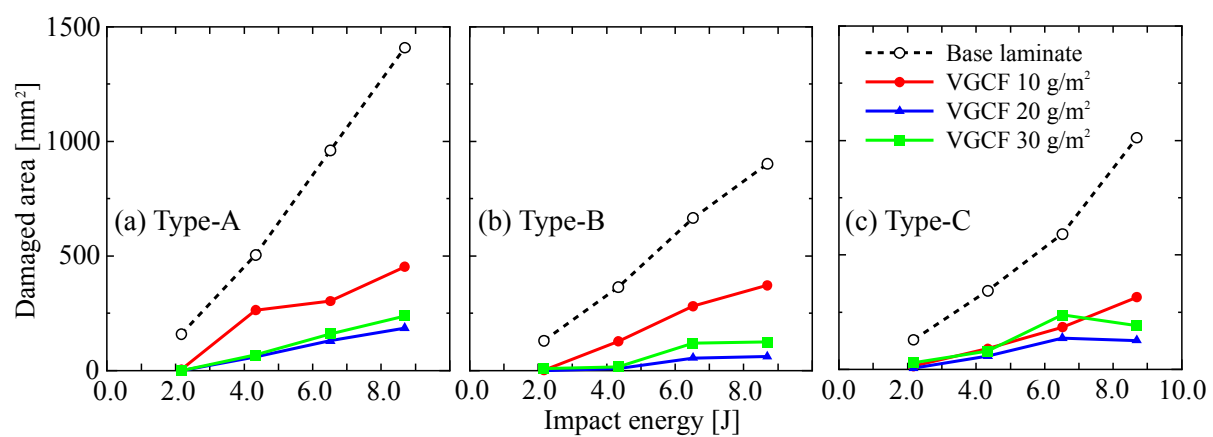

Fig. 8 Relation between impact energy and damaged area of each VGCF/CFRP laminate. 
Next, we pay attention to the influence of an interlayer on damaged area. The damaged area reduced sharply by inserting VGCF interlayer in all type specimens. Although the reduction ratios of damaged area differed slightly by stacking sequence of the laminates, damaged area of VGCF/CFRP laminates became small to about one-third for that of base laminates. As a result of investigating about the difference of the damaged area by the additive amount of VGCF, it was confirmed that the damaged area became the smallest at the additive amount of VGCF $20 \mathrm{~g} / \mathrm{m}^{2}$.

By the way, the influence of inserting the VGCF interlayer on the mode I and mode II interlaminar fracture toughness of VGCF/CFRP laminate was investigated in our previous study ${ }^{(17)(19)}$. It was shown clearly that the mode I and mode II interlaminar fracture toughness was greatly improved by the addition the VGCF. Also, the optimal additive amount of VGCF for improving the interlaminar fracture toughness was $20 \mathrm{~g} / \mathrm{m}^{2}$. These results show the same tendencies as the relation between additive amount of VGCF and damaged area obtained by the present study.

In Ref. (17), it was shown that the interlaminar fracture toughness of VGCF $10 \mathrm{~g} / \mathrm{m}^{2}$ and VGCF $30 \mathrm{~g} / \mathrm{m}^{2}$ are almost equal. However, the bending rigidity of VGCF $30 \mathrm{~g} / \mathrm{m}^{2}$ became slightly large compared with VGCF $10 \mathrm{~g} / \mathrm{m}^{2}$ because the thickness of VGCF 30 $\mathrm{g} / \mathrm{m}^{2}$ was larger than that of VGCF $10 \mathrm{~g} / \mathrm{m}^{2}$. Therefore, the damaged area of VGCF $30 \mathrm{~g} / \mathrm{m}^{2}$ tends to decrease compared with VGCF $10 \mathrm{~g} / \mathrm{m}^{2}$.

\section{Evaluation of residual compression strength}

To evaluate the residual compression strength of VGCF/CFRP hybrid laminates, the compression after impact (CAI) tests were carried out. The relation between CAI elastic moduli and impact energies of VGCF/CFRP laminates are shown in Fig. 9. The CAI elastic modulus of type-C specimen was lower than the other specimens. This was because that the amount of carbon fiber (the number of prepregs) which directed parallel to compression direction was less than the other type specimens. Moreover, the influence of the additive amount of VGCF on CAI elastic modulus was quite small, and CAI elastic modulus of $\mathrm{VGCF} / \mathrm{CFRP}$ laminate was almost same as that of base laminate.

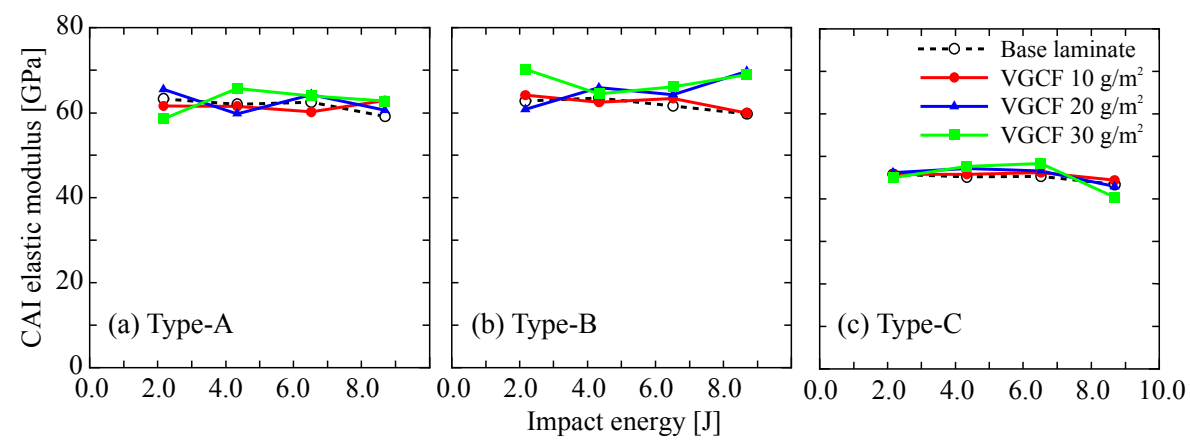

Fig. 9 Relation between CAI elastic modulus and impact energy of each VGCF/CFRP laminate.

The relations between CAI strength and impact energy of each specimen are shown in Fig. 10. CAI strength shows the tendency to decrease with increasing impact energy. In the range more than impact energy $4.34 \mathrm{~J}$, the decreasing ratio of the CAI strength of type-C with increasing impact energy was smaller as compared with that of type-A or type-B. In order to clarify this cause, the side surface of the specimen after CAI test was observed using the optical microscope. Photos of side surfaces of base laminates after CAI tests are shown in Fig. 11. In type-A and type-B specimens, it can be found that the crack is propagating continuously in the thickness direction of the specimen. On the other hand, in type-C, although the delamination size is larger as compared with type-A or type-B, the 
crack of the thickness direction has not progressed continuously. This result was attributable to the carbon fiber orientation angle. Consequently, the stacking sequence with small crossed axes angle of the carbon fibers should be chosen to improve the CAI strength in higher impact energy range.
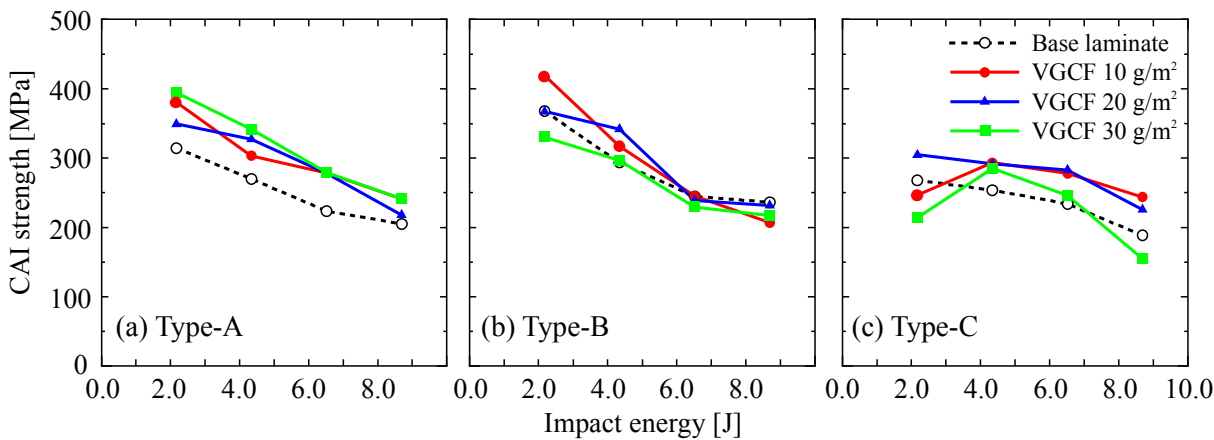

Fig. 10 Relation between CAI strength and impact energy of each VGCF/CFRP laminate.

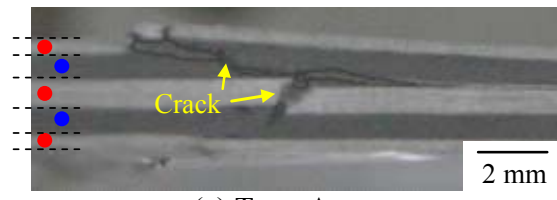

(a) Type-A

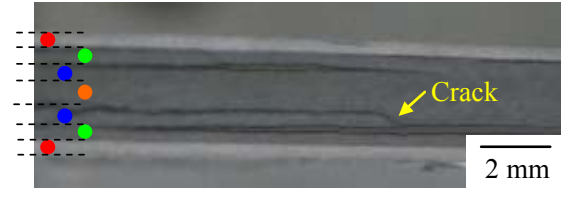

(c) Type-C

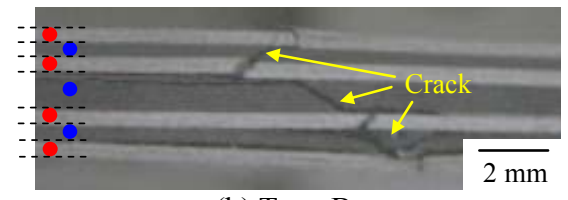

(b) Type-B

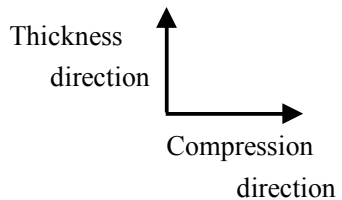

Fig. 11 Photos of side surface of each base laminate specimen after CAI test.

Next, we focused on the relation between CAI strength and damaged area. Here, the damage morphology of each specimen after CAI test can be classified into two groups. In the first group, the impact point becomes the initial fracture point of the damaged area. In the second group, the main breakage occurred at end part of the specimens. The optical micrographs of each compression damages are shown in Fig. 12. Some specimens in which the damages occur at the end part was removed from the following discussion, because the CAI strength of the second group is not related to the damaged area directly. As described before, the tendency of the damage and CAI strength are different between type-A, B (cross-ply) and type-C (quasi-isotropic) specimens. Therefore the experimental results of CAI strength only for type-A and type-B specimens were discussed in the following section.

The relation between CAI strength and damaged area was summarized in Fig. 13. In this figure, it divides roughly into the base laminate and VGCF/CFRP hybrid laminate. The open marks indicate the specimens in which the main damage occurred at the end part of the specimens. The solid marks indicate the specimens in which main damage occurred at the middle part, at the vicinity of the impact point, of the specimens. The solid lines in this figure are the results approximated by the least squares method using only the plots of solid marks of the base laminates. From the approximated result of base laminate, CAI strength and damaged area were in linear relation mostly, and CAI strength became higher with reducing the damaged area. On the other hand, since the results of CAI strength of VGCF/CFRP had large variation, it was judged that linear approximation was inapplicable. However, the tendency of the CAI strength on VGCF/CFRP laminates which decrease as the damaged area increased could be confirmed like the case of base laminate. Moreover, 
comparing the results of both VGCF/CFRP and base laminate, the CAI strength of VGCF/CFRP laminate seems to be lower than that of base laminate if these results are compared with same condition of damaged area. In order to clarify this reason, we paid attention the failure strain obtained by the CAI test. The stress-strain curves of base laminate and VGCF/CFRP laminate (VGCF $10 \mathrm{~g} / \mathrm{m}^{2}$ ) are shown in Fig. 14. Here, since each failure strain should be compared in the specimen which has the same damaged area, the results of base laminate at $4.34 \mathrm{~J}$ and $\mathrm{VGCF} / \mathrm{CFRP} 10 \mathrm{~g} / \mathrm{m}^{2}$ at $8.69 \mathrm{~J}$ were shown in this figure. The stacking sequence of these specimens is type-B, and damaged area is about 370 $\mathrm{mm}^{2}$. This result shows that the failure strain of VGCF/CFRP laminate is falling to about $70 \%$ against that of base laminate. Therefore, the CAI strength of VGCF/CFRP laminate was worsening as compared with that of base laminate.

(a)

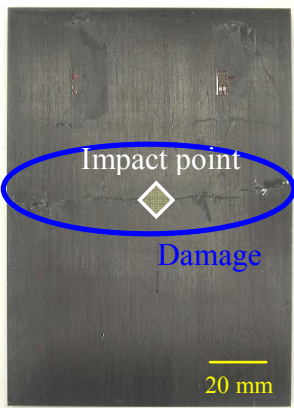

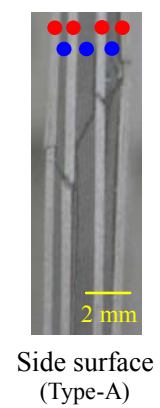

(b)

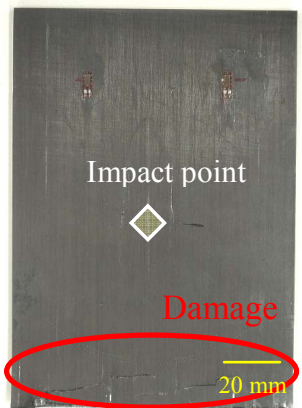

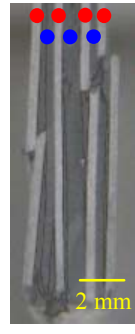

Side surface (Type-A)

Fig. 12 Photos of compression damages occurred at (a) the middle part and (b) the end part of the specimen. (Red marks: $0^{\circ}$ layer, Blue marks: $90^{\circ}$ layer)

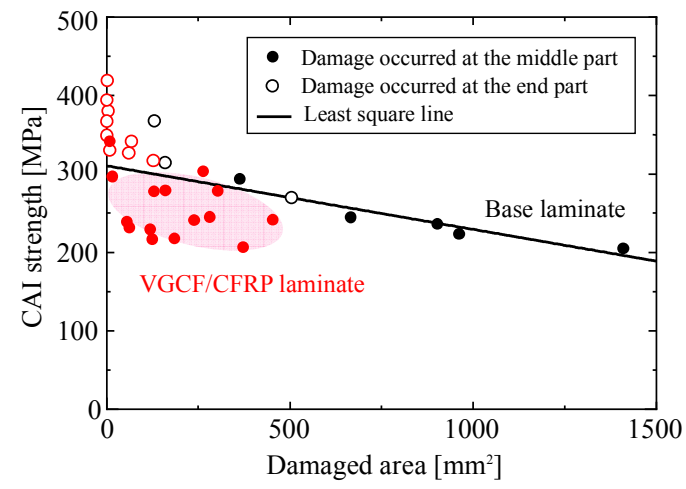

Fig. 13 Relation between CAI strength and damaged area. (Black marks: base laminate, Red marks: VGCF/CFRP laminate)

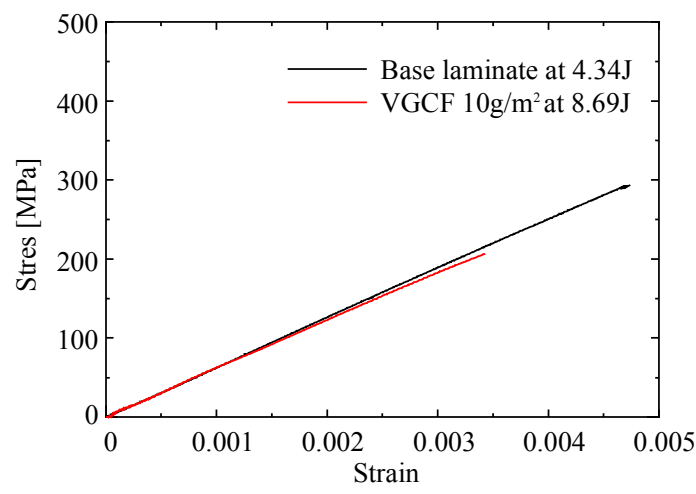

Fig. 14 Stress-strain curves of base laminate and VGCF/CFRP laminate (VGCF $10 \mathrm{~g} / \mathrm{m}^{2}$ ) obtained by CAI tests using type-B specimens. (Damaged area of each laminate: about $370 \mathrm{~mm}^{2}$ ) 
Here, the cause that the failure strain worsened by inserting VGCF interlayer is considered. Generally, in CFRP laminates, several fracture/failure modes, such as matrix cracking, surface micro-bucking, delamination, ply shear-out and fiber breakage, arise complexly when the CFRP laminate is subjected to the impact load ${ }^{(22)(23)}$. Paying attention to this point, the cross-section of the each specimen applied the impact load was investigated in detail about base laminate at $4.34 \mathrm{~J}$ and VGCF $10 \mathrm{~g} / \mathrm{m}^{2}$ at $8.69 \mathrm{~J}$. Figure 15 shows the SEM micrographs of cross-section surfaces for impacted specimens of type-B. $\mathrm{CF}$ waviness is confirmed at $0^{\circ}$ layer in the base laminate, in contrast, CF breakage occurred at $0^{\circ}$ layer in the VGCF $10 \mathrm{~g} / \mathrm{m}^{2}$. Although both of CF waviness and CF breakage decrease the CAI strength of laminate composite, CF breakage reduces CAI strength more notably. Therefore, it was thought that the CAI strength of VGCF/CFRP laminate has diminished rather than that of base laminate. The reason which $\mathrm{CF}$ breakage occurred only in VGCF $10 \mathrm{~g} / \mathrm{m}^{2}$ is because the impact energy applied to the specimen is higher than that of the base laminate.

In Fig. 15, the fracture aspects which have the same size of delamination area for base laminate and VGCF/CFRP were compared. However, the impact energy acting on each specimens are clearly different $(4.34 \mathrm{~J}$ and $8.69 \mathrm{~J})$. Therefore, it is natural that the specimen subjected to more impact energy indicates less CAI strength. As mentioned before, if they are compared on same condition of impact energy for base laminate and VGCF/CFRP, VGCF/CFRP indicates higher CAI strength.

Furthermore, the relation of the CAI strength and damaged area in each VGCF/CFRP laminate (VGCF: 10, 20 and $30 \mathrm{~g} / \mathrm{m}^{2}$ ) is shown in Fig. 16. The decreasing ratio of the CAI strength for the damaged area became larger with increasing the additive amount of VGCF. In particular, the decreasing ratio of VGCF $10 \mathrm{~g} / \mathrm{m}^{2}$ was rapid as compared with that of VGCF 20 or $30 \mathrm{~g} / \mathrm{m}^{2}$. In the each VGCF/CFRP laminates, the CAI elastic moduli were almost constant, and unaffected by the additive amount of VGCF (cf. Fig. 9). Therefore, the reason for worsening the CAI strength is that the failure strain decreased with increasing the additive amount of VGCF. In other words, the brittle fracture behavior became remarkable by addition of VGCF.

From the results of Fig. 10, it is confirmed that CAI strength improved by inserting the VGCF interlayer, however, addition of VGCF to the CFRP laminate is effective only in the case of using specimen with small damaged area. Namely, the reduction of the damaged area using VGCF interlayer has not contributed to the improving of CAI strength directly. CAI strength is determined by various factors, such as the rigidity of each layer (matrix and fibers), strength of the layers, existence of the delamination and transverse crack. In the future, it is important to find out the alternative design of CFRP laminate, using interlayer or adding some agent in the matrix resin for example, to improve the CAI strength and rigidity in consideration of those complex factors.

\section{Conclusions}

In the present study, to improve the impact damage of CFRP laminate which made by unidirectional carbon/epoxy prepregs, CNF/CFRP hybrid laminate was manufactured by inserting the interlayer which composed of vapor grown carbon fiber (VGCF). Moreover, the internal damage occurring by the weight drop impact test and the residual compression strength were evaluated, and the influence of stacking sequence and inserting the VGCF interlayer was investigated. Concluding remarks in the present study are summarized below.

(1) The damaged area was greatly smaller by inserting VGCF interlayer between CFRP layers, and became the smallest at the additive amount of VGCF $20 \mathrm{~g} / \mathrm{m}^{2}$. This was because that the interlaminar fracture toughness of VGCF/CFRP laminate was improved by the addition of VGCF.

(2) The compression after impact (CAI) test was carried out to investigate the CAI elastic 
modulus. CAI elastic modulus was greatly affected by the stacking sequence of prepregs, and became higher with the amount of carbon fiber which directed parallel to compression direction increased. On the other hand, the influence of the additive amount of VGCF on CAI elastic modulus was quite small.

(3) To improve the CAI strength in higher impact energy range, the stacking sequence with small crossed axes angle of the carbon fibers should be chosen. Moreover, CAI strength and damaged area could be mostly denoted by linear relation, and CAI strength became higher with decreasing the damaged area. In addition, the optimal additive amount of VGCF for improvement in CAI strength was $10-20 \mathrm{~g} / \mathrm{m}^{2}$.

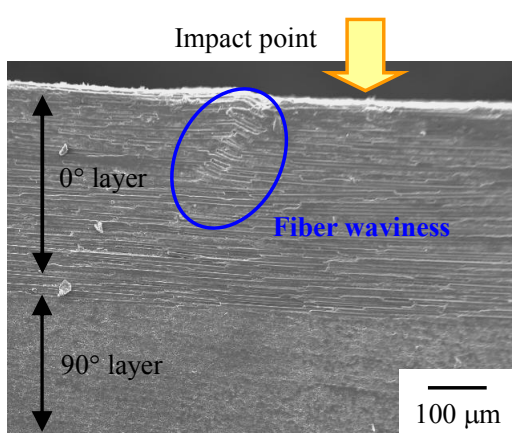

(a) Base laminate at $4.34 \mathrm{~J}$

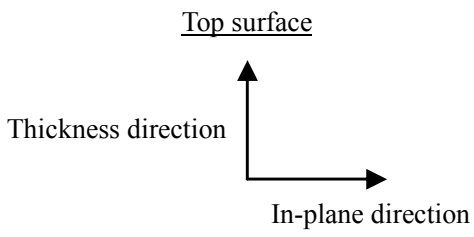

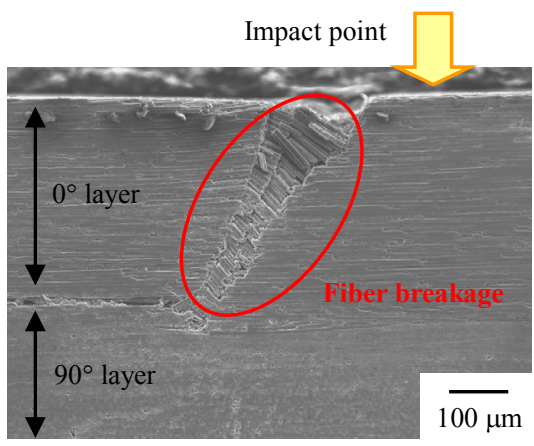

(b) VGCF $10 \mathrm{~g} / \mathrm{m}^{2}$ at $8.69 \mathrm{~J}$

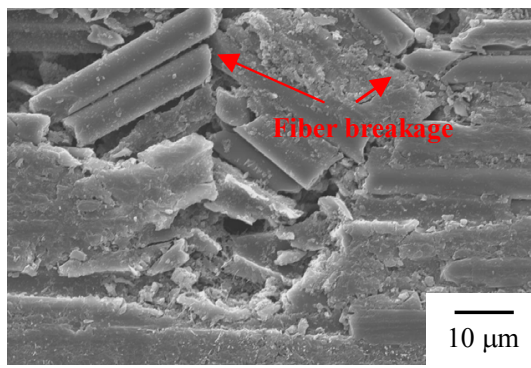

(c) Closeup of fiber breakage

Fig. 15 SEM micrographs of cross-section surfaces for impacted specimens of type-A. (a) Base laminate at impact energy $4.34 \mathrm{~J}$. (b) and (c) VGCF $10 \mathrm{~g} / \mathrm{m}^{2}$ at impact energy $8.69 \mathrm{~J}$.

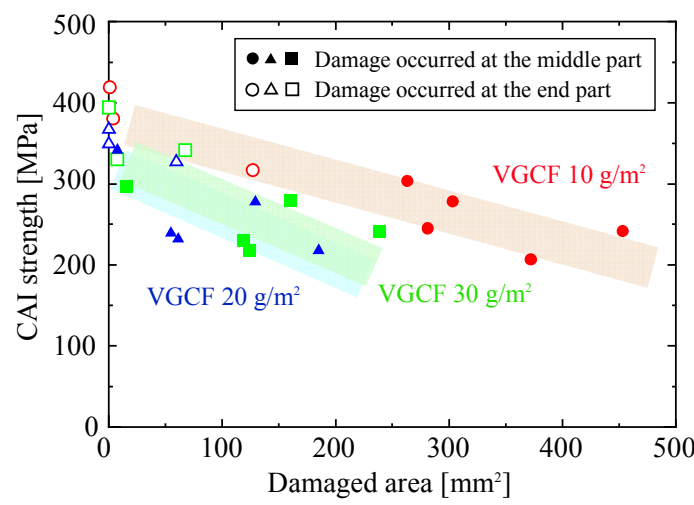

Fig. 16 Relation between CAI strength and damaged area of each VGCF/CFRP laminates. (Red marks: VGCF $10 \mathrm{~g} / \mathrm{m}^{2}$, Blue marks: VGCF $20 \mathrm{~g} / \mathrm{m}^{2}$, Green marks: VGCF $30 \mathrm{~g} / \mathrm{m}^{2}$ ) 


\section{References}

(1) Morgan, P., Carbon Fibers and Their Composites (2005), Taylor \& Francis.

(2) Kawakami, D., Carbon fiber (in Japanese), SEN'I GAKKAISHI, Vol. 66, No. 6 (2010), pp.184-191.

(3) Betzler, M., Slater, C., Strangwood, M., Wallace, E.S. and Otto, S.R., The Static and Dynamic Behavior of Carbon Fiber Composites Used in Golf Club Shafts, Proceedings of 17th International Conference on Composite Materials (2009), CD-ROM.

(4) Shima, K., Press-Forming Method of the FRP Chassis (in Japanese), JP Patent: 2007-181935 (2007).

(5) Sakamoto, H. and Hanai, M., Reprduction of FRP Blade Failure for Wind Power Generators by Lightning and its Mechanism, JSME International Journal, Series A, Vol. 48, No. 4 (2005), pp.465-471.

(6) Glover, B.M., History of Development of Commercial Aircraft and 787 Dreamliner, Aviation Engneering, Vol. 592 (2004), pp.16-21.

(7) Wagner, M. and Norris, G., Boeing 787 Dreamliner (2009), Zenith Press.

(8) Iqbal, K., Khan, S.U., Munir, A. and Kim, J.K., Impact Damage Resistance of CFRP with Nanoclay-Filled Epoxy Matrix, Composites Science and Technology, Vol. 69, Issue 11-12 (2009), pp.1949-1957.

(9) Wang, W.X., Takao, Y., Matsubara, T. and Kim, H.S., Improvement of the Interlaminar Fracture Toughness of Composite Laminates by Whisker Reinforces Interlamination, Composites Science and Technology, Vol. 62 (2002), pp.767-774.

(10) Hojo, M., Matsuda, S., Tanaka, M, Ochiai, S. and Murakami, A., Mode I Delamination Fatigue Properties of Interlayer-Toughened CF/epoxy Laminates, Composites Science and Technology, Vol. 66 (2006), pp.665-675.

(11) Gabr, M.H., Elrahman, M.A., Okubo, K. and Fujii, T., Effect of Microfibrillated Cellulose on Mechanical Properties of Plain-Woven CFRP Reinforced Epoxy, Composite Structures, Vol. 92 (2010), pp.1999-2006.

(12) Higuchi, N., Abe, K. and Kanemasu, M., High Energy Absorbing Composite Structure for Rotorcraft Crashworthiness, Proceedings of 24th International Congress of the Aeronautical Sciences (2004), CD-ROM.

(13) Hojo, M., Nakashima, K., Kusaka, T., Tanaka, M., Adachi, T., Fukuoka, T. and Ishibashi, M., Mode I Fatigue Delamination of Zanchor-Reinforced CF/epoxy Laminates, International Journal of Fatigue, Vol. 32 (2010), pp.37-45.

(14) Mouritz, A.P. and Chang, P., Tension Fatigue of Fibre-Dominated and Matrix-Dominated Laminates Reinforced with Z-Pins, International Journal of Fatigue, Vol. 32 (2010), pp.650-658.

(15) Liu, H.Y., Yan, W., Yu, X.Y. and Mai, Y.W., Experimental Study on Effect of Loading Rate on Mode I Delamination of Z-Pin Reinforced Laminates, Composites Science and Technology, Vol. 67 (2007), pp.1294-1301.

(16) Isa, M.D., Feih, S. and Mouritz, A.P., Compression Fatigue Properties of Z-Pinned Quasi-Isotropic Carbon/Epoxy Laminate with Barely Visible Impact Damage, Composite Structures, Vol. 93 (2011), pp.2269-2276.

(17) Arai, M., Noro, Y., Sugimoto, K. and Endo, M., Mode I and Mode II Interlaminar Fracture Toughness of CFRP Laminates Toughned by Carbon Nanofiber Interlayer, Composites Science and Technology, Vol. 68 (2008), pp.516-525.

(18) Arai, M., Matsushita, K. and Hirota, S., Criterion for Interlaminar Strength of CFRP Laminates Toughened with Carbon Nanofiber Interlayer, Composites: Part A, Vol. 42 (2011), pp.703-711.

(19) Hu, N., Li, Y. Nakamura, T. Katsumata, T. Koshikawa, T. and Arai, M., Reinforcement effects of MWCNT and VGCF in bulk composites and interlayer of CFRP laminates, Composites: Part B, Vol. 43 (2012), pp.3-9. 
(20) Endo, M., Kim, Y.A., Hayashi, T., Nishimura, K., Matsushita, T., Miyashita, K. and Dresselhaus, M.S., Vapor-Grown Carbon Fibers (VGCFs) Basic Properties and Battery Application, Carbon, Vol. 39 (2001), pp. 1287-1297.

(21) JIS K 7089:1996, Testing Method for Compression After Impact Properties of Carbon Fibre Reinforced Plastics (in Japanese) (1996), Japan Standards Association.

(22) Prevorsek, D.C., Chin, H.B. and Bhatnagar, A., Damage Tolerance: Design for Structural Integrity and Penetration, Composite Structures, Vol. 23 (1993), pp. 137-148.

(23) Zhou, G. and Davies, G.A.O., Impact Response of Thick Glass Fibre Reinforced Polyester Laminates, International Journal of Impact Engineering, Vol. 16, No. 3 (1995), pp. 357-374. 